\title{
Education, Research and Innovation - Three Important Pillars in the Process of Implementing the Total Quality Management
}

\author{
Aura COLAN ${ }^{\star}$, Angela-Eliza MICU ${ }^{\star \star}$
}

\begin{tabular}{l}
\hline \multicolumn{1}{c}{ A R T I C L E I N F O } \\
\hline Article history: \\
Accepted March 2021 \\
Available online April 2021 \\
\hline JEL Classification \\
M11, M15, M20, 032, 033 \\
Keywords: \\
TQM, Education, Social Innovation, \\
Planning, Coordination Reform \\
\hline
\end{tabular}

\begin{abstract}
A B S T R A C T
The economic growth, as well as the new workplaces development, are supported by three important pillars - EDUCATION, RESEARCH and INOVATION - and three is greatly emphasized the support of innovative units, thus creating a systemic model. Learning and entrepreneurship training represent the basis for innovation and are influenced by a large number of causes, therefore the education system applies the Management of the Total Quality in order to create values, but this should be backed-up by innovative and advanced strategies.
\end{abstract}

(C) 2021 EAI. All rights reserved.

\section{Introduction}

The labor market has suffered major transformations in the context of the process of economic transition and that is the reason why the long life learning is the essential condition for the adaptation to a permanent changeable environment. These changes have determined the training providers' orientation towards the beneficiary' special needs, the identification of the unsatisfied requests, as well as the initializing of other needs, to fulfil the long term development. Starting with the necessity of improving the means by which the educational system can contribute to education and training, to the influence and development of the human society, the management of education has gradually structured as a new conception of the approach of educational activities.

The establishment of an adequate quality framework is the assignment of the systems of management of quality. The needs of the participants to the learning process are extremely important, alongside with the requests of the community and of the employers, expressed through a better planned framework, based on coordination and cooperation. The key for the improvement of the pupils and students' performance is a well-developed strategy for the improvement of education. There are a large number of strategies to improve the education.

One of the strategies might include better training materials, the curricula readaptation, the highlyuse of technologies, new scholar structures (the reduction of several levels of bureaucracy to be found in the majority of education system institutions), the professional development, multiple complementary strategies, such as educational staff training and summer schooling, or more parents' implication. The quality of education depends on the quality of the teaching staff, and at the same time, of the education system management regarding the students' capacity and willingness to learn, as well as the insurance of the quality of educational services.

The teaching staffs are the essential resource for the efficient implementation and delivery of the educational policies. The maintenance and improvement of the educational standards are possible by means of the teaching staff. The lack of management or the default management of the human resources in the educational system reduce the performance of the system, no matter how much we invest in other resources. The management of the system implies all the system elements altogether with the processes of an organization.

We will consider key items those items of the system of an organization the can emphasize the relevant factors of quality.

- The input systems shall include the organizations together with internal and external persons whom from an organization receives products and information, such as - suppliers, traders, customers; 
- The inputs - are the material, human and financial resources necessary for the achievement of the target results;

- The transformation processes of the "inputs" into "outputs" should be efficient in order to fulfil the quality demands;

- The outputs are represented by the products and services achieved by the organization;

- The output systems include the organizations and the persons that receive the products and services, obviously fully satisfying the customers' needs and expectations.

The perception of the customers' needs, their reflection in the quality of the finite products must be the basement of the decisions and measures undertaken in all the other items of the system. Teachers are supposed to talk to their pupils or students all the time, to get the feed-back of their performance, thus implementing the European models of excellency - Lean, Six Sigma, Business Process Management (BPM), although these are deficient when considering the critical concepts of quality, such as the social responsibility and the needs of the interested parties, which are limited for both the direct and indirect beneficiaries.

Last but not least, the study reveals which the objective of the following paperwork is, that is, to present proofs regarding the implementation of the QM models in the education system in the South-East Region of Romania, and, at the same time, to improve the research in the QM domain.

The article is structured as follows: a general presentation of the quality management, emphasizing the QM models, followed by the survey through on-line interview methodology. Afterwards, we shall discuss these results and, analyzing them comparatively, we shall revise the literature regarding the models of quality management in education, alongside with a research among the academic staff of the universities in Galați. Moreover, the conclusions include critical triggers of success, obstacles and benefits, all in all confirming and completing the pre-existing literature, the need of training programs, as well as the need of new abilities, the main services provided to the young people, the themes identified by the respondents in the future training programs, the directions of improving the training system of the academic staff, and not on the last place the training modalities. On the other hand, the infrastructure, the limitations of the human and financial capital, the limited implication of the interested parts, together with the measurement of a complex series of performance indicators, all together represent barriers that enrich the analysis; whereas the implementation of the QM practices may resolve the problems and propose solutions at the same time.

\section{Literature review}

The study concerning the use of the European model of TQM as referential of the management and the improvement of the quality of the education organizations offers practical appliance and utility of the theoretical concepts. The EFQM model contains nine criteria (fig. no. 1) based on which the progress achieved by the education system are evaluated through TQM.

There are five criteria that belong to the "Determinant Factors" group: leadership, staff management, policy and strategies, resources and processes, and they all refer to the way in which (HOW?) the results were achieved. All of them represent causes or premises.
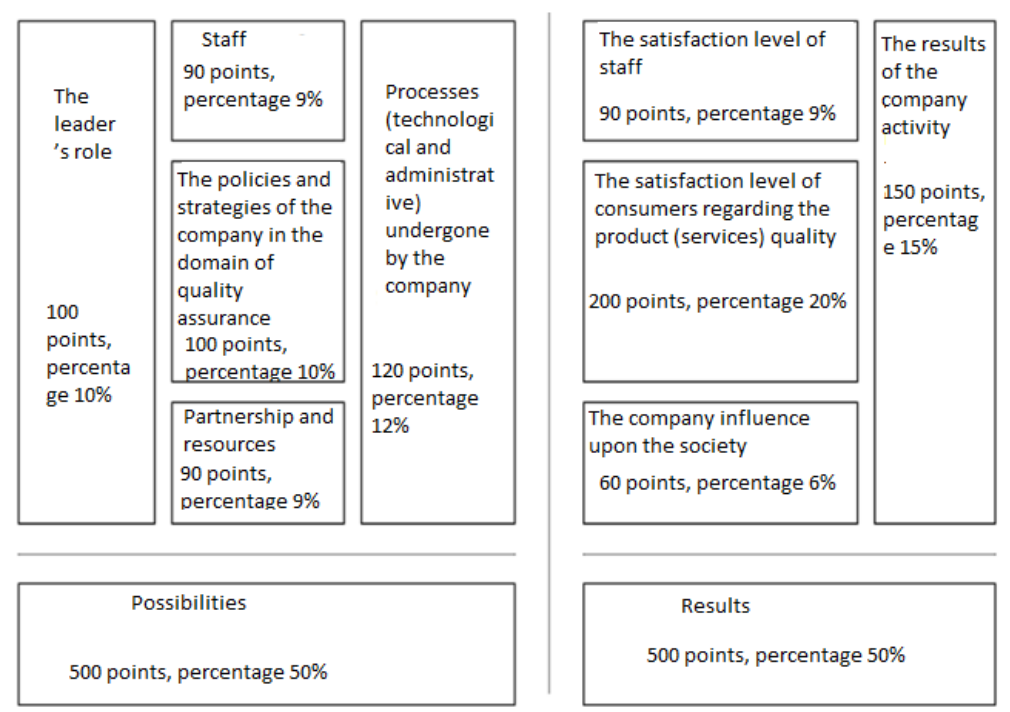

Figure 1. The quality achievement Award Excellence model

Source: Quality achievement Award Contest 2017. Annex No. 1. [on-line]. Available: http://chamber.md/cci-a-rm-da-startul-înscrierii-laconcursul-premiul-pentru-realizări-în-domeniul-calității/

For example, in pre-university education besides the consultation of P.R.A.I. (Regional Plan of Acting in Education) and P.L.A.I. (Local Plan of Acting in Education), from the area where the school is located, 
directors and those involved in the planning must also take into account regional and local education action plans of neighboring counties/ regions to address common problems and developments in different counties/regions. This is very important for "specialized schools", which offer specializations at regional or national level. For some time, schools have developed plans, setting out the development directions for a number of areas, such as new skills, professional development of staff, renovation of buildings, purchasing of new equipment. School action/development plans are plans to develop IPT in an individual school or group of schools. These plans define the purpose and role of each school and the role it will play in implementing the IPT development program at national, regional and local level. School directors and staff increasingly need to recognize the importance of working in partnership at both regional and local level, of carrying out rigorous self-assessment activities at both institutional and individual levels, and of an approach, to put the customer first. Other organizations, such as Employment Agencies, Local and County Councils and local employers, will also be encouraged to integrate R.P.A.E. and L.P.A.E. priorities into their own planning activities, in order to ensure a "unified" approach to local planning.

S. A.P. (School Action Plan) describes how each school will: contribute to regional and local priorities, targets and actions; improve the quality of education and training provided by school; respond to labour market needs and individual needs; fulfill the reform program for P.T.E. (Professional and Technique Education) help to ensure a properly qualified workforce in restructuring areas; contribute to lifelong learning programs for young people and adults; work in partnership with other schools, social partners and authorized supply organizations; effective services and establishment of local collaboration networks; ensure efficient use of resources (physical and human). The modern education process can focus on moving from teachers to students. Knowledge transfer is two-way and the teacher's monologue is transformed into a student dialog. They play an active role not only in the questions they ask and in the discussions they generate, but also by using more resources to build knowledge. In this process, the time spent on the courses is very long, reduces and increases the time for laboratory and individual study hours.

Four criteria are part of the "results" group: Staff satisfaction, customer satisfaction, social impact and operational results and reflect what was achieved or achieved (CE?), so they represent effects. In this way, the model highlights a cause-effect relationship of how the results were achieved. By analyzing the weights for each criterion, it can be pointed out that the most important criteria in performance evaluation are: Customer satisfaction (20\%), operational results (15\%) and processes (14\%).

Results of the application of the School Action Plan at South-Eastern Region level indicate that over time they have not been consistent with the management plans, so our managers have middle (still at the bottom) skills in leadership and communication (providing feedback) and we are going to be in the same position as the president. We have an explanation for this also for the indicators related to team development, conflict resolution or time management. These managers need to be judged with the measure, because one who is not involved and unsound, neither can delegate tasks, communicate effectively or excel in leadership, nor can develop a team, nor can have brilliant results in participating with others in the smooth running of the institution's activity.

The benefits of applying the model could be:

1) providing reliable information to understand and understand the needs and expectations of pupils and parents;

2) allowing appropriate organizational objectives to be set according to the needs and expectations of the recipients of education;

3) improving the image of educational institutions;

4) creating the best conditions for the loyalty of direct and indirect beneficiaries and teachers;

5) allowing the satisfaction of beneficiaries to be measured and analyzed and actions to be initiated on the basis of results;

6) managing the relationship with direct beneficiaries, ensuring a satisfactory balance between other direct stakeholders (parents, teachers, schools, faculties, entrepreneurs, society, etc.).

\subsection{Quality management requirements}

Quality management, at the level of any organization, can only be achieved by implementing a quality management system that manages (systemic) the processes in the organization. Such a process includes several steps for successful implementation:

1) Identification of the needs of beneficiaries and all stakeholders;

2) Setting the quality objectives of the educational establishment;

3) Determining the policies, processes (process map) and responsibilities needed to achieve the quality objectives;

4) Establishing and providing the resources needed to achieve the (quality) objectives;

5) The establishment and application of methods for measuring the effectiveness and efficiency of each process;

6) Determining the means of preventing non-compliance and eliminating the causes thereof;

7) Establish and implement a process of continuous improvement of the quality management system. 
In particular, two approaches are increasingly present in educational environments: Systemic and process. Therefore, addressing a specific quality management strategy at the level of the education system becomes a safe path to progress on a stable path, generating the conditions for the educational entities in the system to achieve performance and standards required by contemporary society. On the other hand, today's Romanian school will manage sooner or later to actually go into an organizational paradigm, to the detriment of the existing institutional one. This will involve a broad accountability of the school "organization" management team. The transition to the new paradigm will force schools to take decisions based on a very serious quality management and to be anchored in contemporary realities, which are marred by a number of extremely important factors: environment/community in which it operates, the labor market in which it evolves, the needs of both customers and stakeholders in the development of the organization, etc.

This leads to an (inherent) approach to quality management at school level based on at least two fundamental elements, previously mentioned: Systemic and procedural. Moreover, the legislative framework, with an exaggerated change dynamic, forces schools to evolve more and more "rationally" and appropriately to the resources at their disposal. This is why there is no doubt that much more is needed than rigorous application of institutionally-imposed rules. Quality management is required implemented at the level of the organization and functioning consistently, efficiently and effectively.

The Romanian model of excellence, also called the Romanian quality Prize "J. M. JURAN", is structurally very close to EFQM's model of excellence. Therefore, the overall basis for quality management systems is a systematic and cyclical process of definition, planning, control, evaluation, change and improvement. This study would like to answer the following research questions on training, teacher involvement, motivation for quality education in university education in the South-East region:

1) What are the obstacles to QM practices in schools in the field of training?

2) What are the QM models or practices that have been implemented in higher education institutions?

3) What are the benefits of QM practices?

This work presents and discusses the results. Furthermore, it suggests gaps and directions for future QM research in higher education.

\subsection{Quality of education}

Any institution shall develop its quality management system taking into account national regulations, objectives and experience. SMSPs are intended to contribute to continuous improvement of the education and research process in the respective institutions and to other related services provided by educational institutions.

The fundamental elements underpinning any such system are:

- the expectations of pupils/students, employers and other stakeholders;

- creating an environment that is fit for performance across all the dimensions of the activity;

- addressing the quality issue from a strategic perspective: mission, values, principles, policies, strategies, objectives, etc.;

- continuous control and improvement of the processes within the institution;

- involving and empowering staff;

- establishing relevant quality indicators and their internal evaluation;

- documenting the system in order to provide objective evidence that would create confidence in quality management.

If the organization is "educational" - school or university/faculty, it will not be an exception to the implementation of an SMQ based on these steps. The Commission notes that the aid is granted to the following companies: The general basis for quality management systems is a systematic and cyclical process of definition, planning, control, evaluation, change and improvement. Most of the success factors identified in scientific literature can be found in one of these categories. These requirements are similar for all types of organizations. The comparison of typical functions of an organization's value chain (Porter, 1985) should be the quality that is determined mainly in the primary functions). In addition, the secondary function (human resources, procurement, etc.) should be taken into account. In his view, each of the functions of the undertaking must be aimed at achieving these operational objectives (Kelada, J., 1990).

It follows that quality management is a constituent part of the company management. Kelada believes that quality management should not form a technician's appetite. Its responsibility lies with the top management and managers of each facility in the enterprise. The role of the implementation of quality models in the assessment of educational institutions is - the QM implemented in educational institutions is a comprehensive management approach that requires the contribution of all participants to the organization working for long-term benefits for those involved and society as a whole. The balanced Scoreboard is a performance/strategic management system that uses four measurement perspectives: Financial; customer; internal process; and learning and growth. Malcolm Ballet based on a performance excellence framework that can be used by organizations to improve performance. Seven criteria categories: Leadership; strategic planning; customer and market orientation; measurement, analysis and management of knowledge; concentration of human resources; process management; and results. ISO 9000 Series - International 
standard for generic quality assurance systems, continuously concerned with improvement through preventive action. The elements are customer quality and Regulation, requirements and efforts to increase customer satisfaction and continuously improve. In this study, we have turned to EFQM to assess progress toward excellence.

The following study identifies the main barriers or obstacles to the successful implementation of QM: 1.Lack of leadership commitment, because many managers are appointed politically

2.Poor vision and poor achievement of the management plan, if any

3.Influence of state educational policy through permanent and defective modification of legislation in this field

4.Lack of highly qualified professionals, especially in the management and marketing of the institution

5.Lack of knowledge of self-assessment mechanisms

6.Resistance of institutional assessment/change

7.Poor coordination between employees and departments

8.Lack of interest in the application of quality models by staff employed

9.Wait for immediate results without establishment in the medium to long term

10.Instability of leaders and departments due to political involvement in the management of the institution

11.Rigid organizational structures, with top-down decisions, especially in the policy of recruitment and employment of staff

12.Lack of clarity about role and responsibilities, with no real consequences for teachers not being involved

13.Lack of employee involvement, lack of motivation, involvement and management - teachers/pupilsparents - employers.

\section{Research methodology}

The fundamental elements underpinning any system are the expectations of pupils/students, employers and other stakeholders, the creation of an environment that is appropriate to performance across all dimensions of the activity, the strategic approach to quality should lead to a paradigm shift by focusing on matching client skills to market requirements, the real economic environment, rather than investing in job search that meets customers' wishes.

This study aims to explore the skills needs on the labor market for better matching of individual skills, skill levels, labor potential and labor market opportunities. Renewing skills and qualifications throughout the working life cycle can be a viable solution to alleviate the difficulties of (re)entering the labor market, especially young people. The main aim is to match supply and demand for labor addressed to jobseekers, including those belonging to vulnerable groups, and to identify aspects that enable customers to take a position that is best matched with their capabilities, including also the possibility to improve their professional profile through continuous on-the-job training.

Sample construction - the questionnaire was applied to members GT - 100 students/response 84 teachers/ response 84\%, 30 teachers/response 12 teachers/response rate 40\%, 20 employers/response 14 employers/response rate 70\%, 30 graduates/response 14 graduates/response rate $47 \%$.

Drafting of the data collection tool - the questionnaire contains different types of questions: Factual questions that provide information about objective, verifiable facts (home, studies, profession); questions of opinion recording subjective information such as attitudes, opinions, beliefs, values, feelings, interests; They are obtained directly by communicating with subjects; questions of motivation to explain the causes or conditions for specific actions. They are much like opinion, but distinct in that, based on them, behavioral predictions can be made. Knowledge questions used to test the level and quality of information that subjects have in a particular field. They are used very rarely and only when they are necessary, because they create an examination situation and can block communication.

\section{Results and discussion}

At present, in 2020 for the South-East region, a number of key issues were identified that require coherent and appropriate public policies to be developed and implemented so as to support economic development and job creation that is appropriate to labor supply:

1. the decline in population in this region, but also in Romania in general, with serious effects on the labor and labor market;

2. the low activity rate of young people in the region is an issue that requires consistent and consistent support for the implementation of public policies supporting youth employment;

3. the high proportion of young people not in education, work or training (NEETs), but also the continuous increase thereof, is worrying, given that they are at a very high risk of poverty in the long term. If no measures are taken in respect of education or employment in this category, it will represent a "burden" on the state budget;

4. the increase in the number of unemployed people with higher and middle education is another challenge that the institutions responsible must face and for which specific measures and actions are needed;

5. regarding participation in ep learning programs Throughout their lives were below the national level, and well below the minimum progress required by the EC. This measure must be supported and developed as an important activity for the continued preservation and adaptation of professional skills; 
6. early school leaving is a phenomenon that has direct repercussions on the labor market and this aspect should therefore be seen in an integrated way alongside employment policies.

In the case of this research, the analysis of the results on the socio-demographic characteristics of the study participants generally showed the same trends as the official data of the target group, which confirms the representativeness of the sample chosen in the research. The urban-urban distribution, we believe, reflects the real situation, thus highlighting the problems of both demographic categories.

The economy of the South-East region has been deeply affected by the fast-moving international economic integration, labor market segmentation, the protection of certain economic sectors, the accelerated development and deployment of new technologies, the decline in working-age populations and the aging population, an increase in the phenomenon of labor migration to other States, which have had major consequences for the labor market and have led to a widening gap between employment structures, with implications for the supply-demand ratio.

The urban-urban distribution we believe reflects the real situation, thus highlighting the problems of both demographic categories.

It is to be noted that the high proportion of young people in the target group, over $90 \%$ of students by 25 years, $50 \%$ of teachers have up to 40 years of age and graduates are up to 25 years of bachelor and, correlating to, the low share of people in the 55-64 years' period as regards the educational level of people with difficulties in the labor market, the survey showed that the most important share is among rural student respondents.

Low labour participation in continuing training programs - in contrast to increasing training needs (for businesses, employees, unemployed), arising from occupational mobility accentuated by economic restructuring processes, updating needs and matching of skills to changing needs in the workplace, etc. provides schools with an opportunity to be actively involved as providers of adult training, taking into account:

- increasing the skill level of human capital and training new skills to adapt to technological and organizational changes in enterprises

- matching of qualifications with the workplace

- retraining according to labor market needs

- recognition and exploitation in professional experience and skills acquired by the ep formal and informal path

- diversification of the training offer and adaptation to the needs of the target groups: e.g. distance training programs, consultancy, etc.

The situation in the local labor market - the Southeast region shows $47 \%$ lower labor demand than some qualifications and for another $41 \%$ point to the reverse.

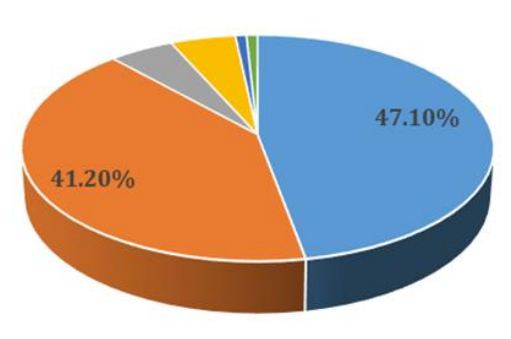

$$
\begin{aligned}
& \text { " The demand for work is } \\
& \text { lower than supply } \\
& \text { " The demand for work is } \\
& \text { higher than supply } \\
& \text { " The demand for work is } \\
& \text { balanced with supply } \\
& \text { " Better services of the } \\
& \text { County Emploment Agency } \\
& \text { - Internal training budgets } \\
& \text { - Others }
\end{aligned}
$$

\section{Among the benefits of training courses, young people note:}

\section{4 answers}
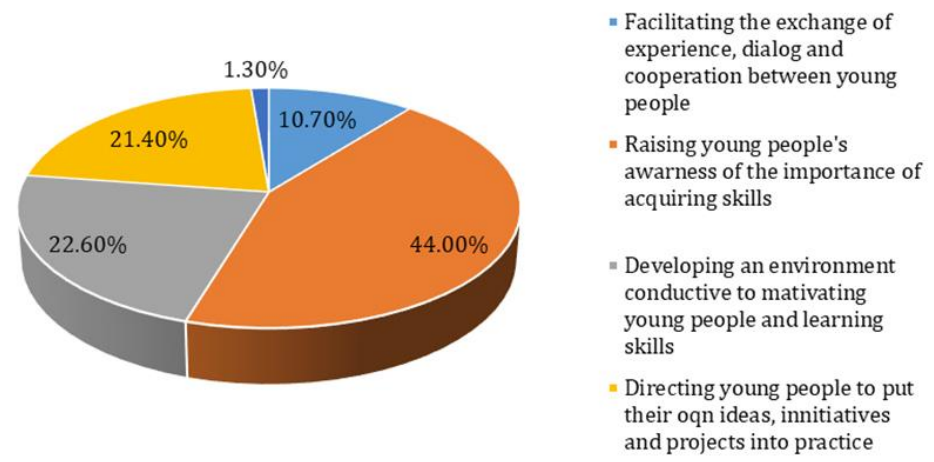

On the other hand, teachers chose to train themselves for the following reasons - mobility, students and students involved in international fairs, working visits, to complete vocational training, the challenge of learning something new and the interaction and team working in projects, the approach of new teaching 
methods, Knowledge of modern/classic learning efficiency techniques in teaching, cooperation with the private economic environment, implementation of research projects in partnerships, knowledge of new methods of educational mentoring in higher education, development of skills to promote and enhance the quality of student training, knowledge of methods, Modern learning efficiency techniques and processes, development of professional skills, examples of good practice, extension of collaboration in different fields of work, learning new information/methods, updating old information, knowledge of the approaches to teaching and studying relationships in the academic world.

The offer of professional refresher courses, existing at the level of the Romanian education system, satisfies your need for $42 \%$ personal and professional development and must be $58 \%$ of the traffic.

In the moderate scenario, occupational groups with slight job increases expected would be physics and technology technicians, fixed-line operators and equivalent workers. The number of jobs available for operators in machinery, machinery and assemblers of machinery, equipment and other products is maintained at approximately constant level Developments leading to negative values suggesting job losses in the region's economy appear to affect groups of farmers and skilled workers in agriculture, models, models, models and sellers in shops and markets, workers in personal and protective services, public service officials. For the other occupational groups, jobs are projected to be available in most of the forecast range, but in a downward trend.

Young people therefore state the reasons for taking training:

\begin{tabular}{|l|c|c|}
\hline The need for training programs & Frequency & Percent \\
\hline a. Professional development & 53 & 63,10 \\
\hline b. Career reorientation & 4 & 4,75 \\
\hline c. Personal development & 24 & 29,76 \\
\hline d. Advance on job & 2 & 2,38 \\
\hline Total & $\mathbf{8 4}$ & $\mathbf{1 0 0}$ \\
\hline
\end{tabular}

The disparities in education levels in rural areas from urban areas mean that:

- systemic measures to increase the overall quality of rural education

- ensuring equal access to education under quality conditions

- measures to support the continuation of education by students from rural areas and economically and socially disadvantaged groups.

Young people therefore believe that they need the development of new skills:

\begin{tabular}{|l|c|}
\hline New skills needs & No. Pers. \\
\hline $\begin{array}{l}\text { Inclusion of current information from the business } \\
\text { sector }\end{array}$ & 29 \\
\hline Computer usage in learning & 4 \\
\hline Internet usage in learning & 1 \\
\hline $\begin{array}{l}\text { Foreign languages (English, French, Italian, Spanish, } \\
\text { German) }\end{array}$ & 6 \\
\hline $\begin{array}{l}\text { Human resources (Inspector, recruitment and } \\
\text { evaluation specialist, L.H.S. (Labour Health and } \\
\text { Security) specialist) }\end{array}$ & 12 \\
\hline $\begin{array}{l}\text { Management (general, project, financial) and } \\
\text { entrepreneurship }\end{array}$ & 10 \\
\hline Accountancy & 1 \\
\hline Marketing & 1 \\
\hline Secretariat and office & 6 \\
\hline Travel agents and hotel services & 14 \\
\hline
\end{tabular}

There have been structural labor market problems identified by respondents, such as: 


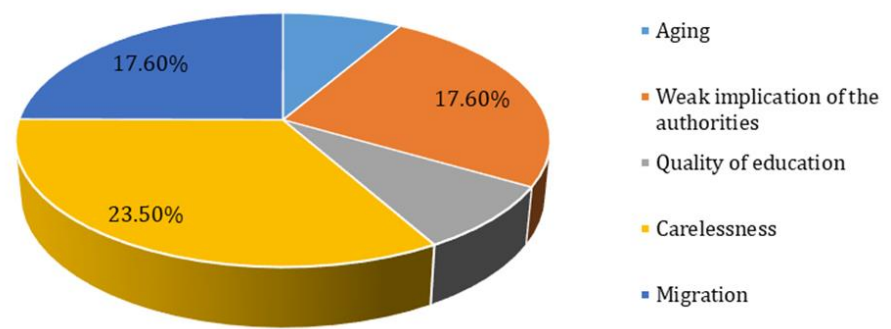

Therefore, for the respondent, lifelong learning aims to acquire more information and to acquire new qualities and opportunities to know the innovative technologies that are emerging on the market quite frequently, so that we can use them and will make my work, personal and professional development easier, improving all skills, continuing learning and learning new information, improving the relevance of education and training systems. The main obstacles to modernizing initial training in terms of the severity of the problem:

a) inadequate and outdated legal regulations

b) lack of financial resources, especially of the equipment and facilities

c) lack of human resources, lack of motivation and of proper competences

d) lack of examples of good practice

e) lack of cooperation possibilities

f) lack of students' motivation regarding...
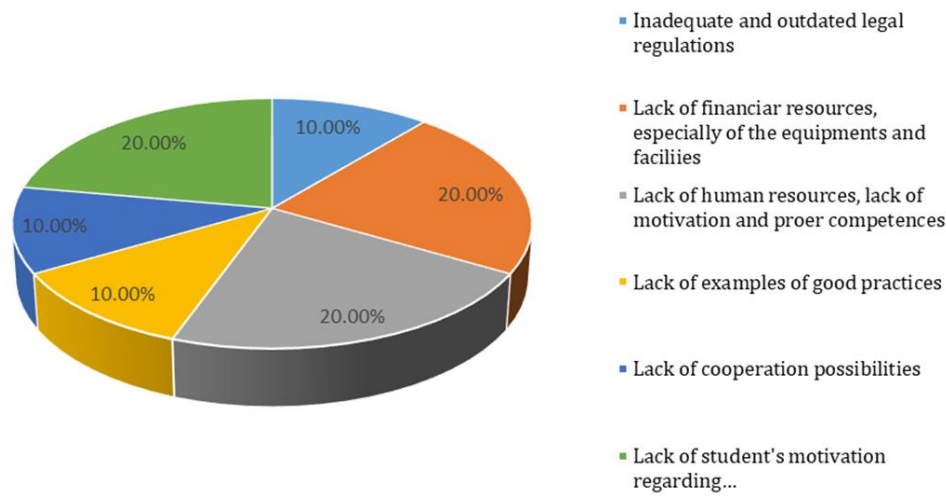

Most respondents, in each category analyzed, were skeptical about the likelihood of finding a job in the near future. The most skeptical are young people in the 15-24 age group, of whom 64\% said they needed to adapt in the workplace, $28 \%$ had the necessary adaptation skills (according to their job description, knowledge, communication skills, digital skills, knowledge, skills, and knowledge of the workforce). Programming the beginner level does not matter much experience, but the desire of the person who is committed to learning and to being understanding matters, mainly a solid basis of functional skills of several operational skills that demonstrate the ability to put into practice the concepts studied. (E.g.: Sale, negotiation, market research, team management, etc.), the candidate has at least one foreign language, is adaptable, results-oriented, innovative, have analytical capacity; be results-oriented and have the capacity to solve problems; communicate effectively; To continuously learn foreign languages, training courses, basic knowledge in it - advanced knowledge in the chosen field of study as well as software skills, knowledge Digital marketing, and 7\% think that they need to retrain and the ways of employment, ways of finding jobs were very different.

The main requirements are:

1) minimum practical experience

2) basic knowledge according to the post;

3) the graduate's wish to move to the firm;

4) seriousness and perseverance

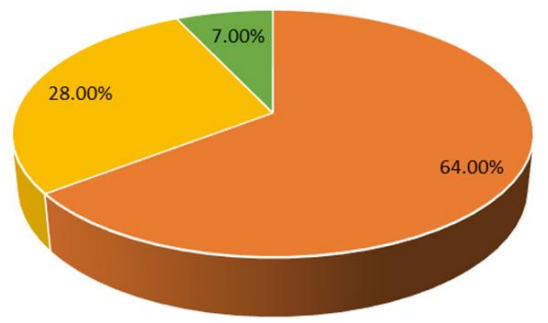

- Respondents need to adapt in the workplace

- Respondents have the necessary

adaptation skills

- Respondents need to retrain 
How did you find a job?

- Written and online press

- County Employment Agency

- Family, friends, acquaintances

- Recruitment from college

- Recruitment companies

- By acquaintances

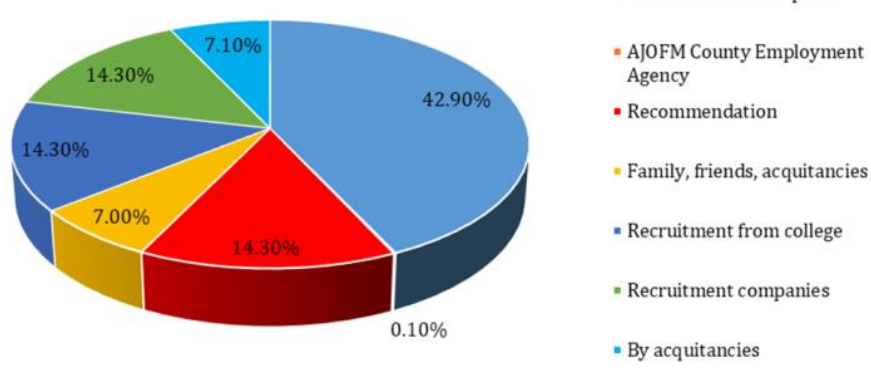

The analysis of the survey data shows that the interviewees have a fairly high level of information, given the characteristics of the group concerned. This shows roughly equal proportions between those who are interested and informed about the labor market and those who are poorly or not-at-all informed.

The level of information on training opportunities is an indicator of the flexibility and adaptability of individuals to the needs and evolution of the local and regional labour market. The analysis of the data obtained showed that all categories of respondents have little information on actual training opportunities to facilitate their access to the labor market.

The topics identified by respondents in future training programs cover different themes, for example:

a. Harmonization with the current European context (key competences areas, European qualifications Framework)

b. New educational theories (constructivism, centering on Student)

c. To emphasize the application dimension of concepts and theories in the field of entrepreneurship

d. New educational theories (constructivism, centering on Student)

e. Cooperation and cooperation with economic operators

f. Differentiated teaching - learning strategies

g. Fostering the autonomy and creativity of students

h. Differentiated teaching for students with special learning needs

i. Human resources consultancy for organizational customers, in issues of: Communication, teamwork, employee motivation and performance stimulation,

j. Recruitment and selection of appropriate staff for organizations,

k. Personnel assessment using specific assessment tools (questionnaires, tests), including: Performance evaluation, skills assessment, workplace satisfaction assessment or psychological testing,

1. Job analysis and job descriptions design,

$\mathrm{m}$. Personalized training for company employees.

The learning skills deemed necessary to perform teaching under the best possible conditions relate to digital skills, adaptability, career advice for young people, entrepreneurial and communication skills, methodological skills, communication and networking with students with the ECI, capacity for innovation and adaptation to macroeconomic change, Adaptation and connection to the labor market, adaptation to socioeconomic change, psycho-pedagogical skills, professional skills, intercultural skills, foreign language (EN), scientific research, knowledge of international databases, skills on the ability to create, discover new methods of information transmission, managerial skills, innovative teaching methods. Digital skills

a) Entrepreneurial skills

b) Methodological skills of communication and inter-relation to students

c) Personal and professional development

d) Career counseling

e) Capacity to adapt to changes, innovation

f) Long-term development

g) Others 


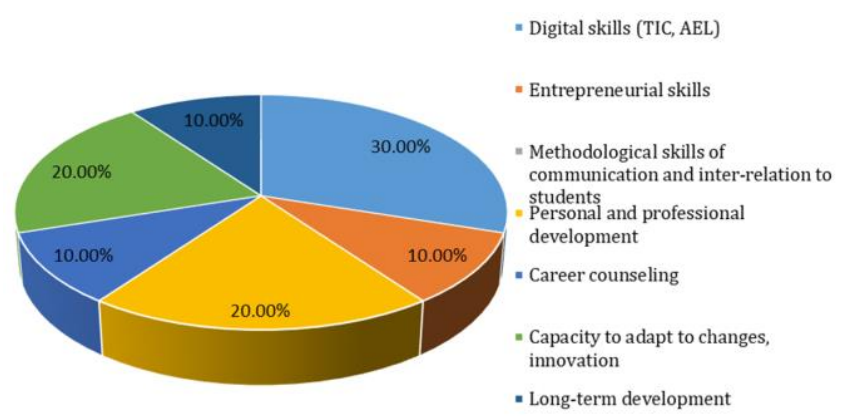

Ways of improving the teacher training system are primarily developing a national skills system agreed by employers and the most used training methods suited to continuing vocational training objectives are a combined form of training (face-to-face and online) and the most sought-after way short courses for improvement and interactive seminars.

a. familiarity with methods of intervention for persons ..

b. development of mechanisms for organizing and monitoring practice

c. development the professional skills system at national level

d. improving recruitment and career support systems

e. the establishment of a body of expert or certified mentors through training

Within each category of respondents, those with higher education would participate more in completing vocational training. Higher education graduates are thus willing to improve their training to $100 \%$. As the vocational training for all categories that are or wish to enter the labor market is accomplished through the Romanian education system, it would be interesting to know the level of development of the educational market in the field of continuous professional training. This level may be assessed in the light of the quality of the educational services provided by specialized vocational training centers. But the permanent restructuring of education in our country makes it impossible to place it on solid foundations. The educational market in the field of continuing vocational training is being trained, which is why its level of development is not very high. Increasing competition between organizations providing such services and, consequently, improving the quality of the services provided, which are customer-centered, can benefit both beneficiary companies and those wishing to enter the labour market.

a) Unstable legislative framework on the labor market

b) Quality of the public services on the domain ...

c) Quality of private services on the domain ...

d) Quality of the education services

e) Lack of qualified employees

f) Demography

g) Migration

h) Lack of communication on the labour market and ...

i) I do not know.
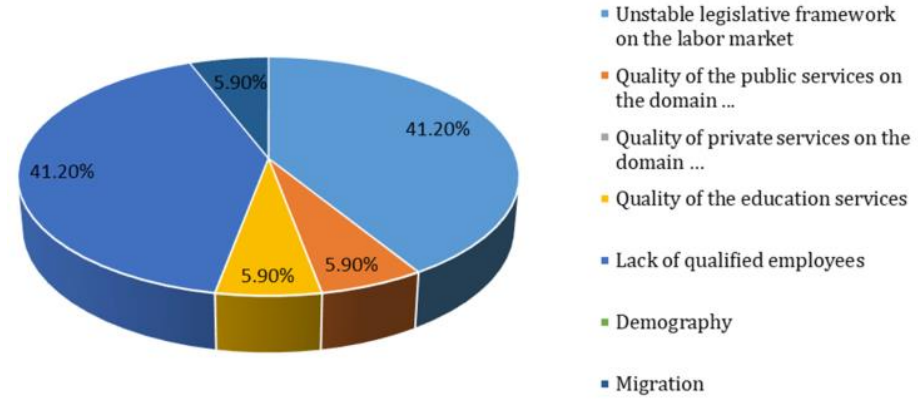

This section analyzed the target group's needs in relation to the labour market, the need for professional and personal development, the perceptions of the target group in relation to the training courses proposed by the project team. One solution aimed at correcting labor market imbalances, especially in structural terms, and reducing the mismatch between training and training of the workforce with the specific features of jobs at a given time is retraining. The orientation and qualification of individuals in the professions required on the labor market requires that job mobility be anticipated both in relation to technical changes and in line with job restructuring forecasts, it therefore justifies the importance it attaches to the acquisition of skills to enhance its (re-)integration into employment. 


\section{Conclusions}

Regardless of their skills in the labor market, $100 \%$ of respondents consider it absolutely necessary to take a training course, regardless of student status, teacher status, graduate status, employers, because young people recognize the need for training to increase their chances of finding a job. Similarly, higher education graduates are open to this possibility, and we also note that there are no differences between residence, with both urban and rural respondents following the general paternity of preferences. Respondents mostly participated in specific courses in their field of activity, but we also note an interest in more effective communication or management courses.

Teachers' respondents prefer $40 \%$ to improve student training programs and only $10 \%$ consider these programs obsolete.

Employers take into account the following requirements from the education system, such as investment projects and facilities (including irrigation) for agriculture; development of the internet and PC network for rural areas; support for children's educational performance through scholarships for high school and/or university in general and especially for rural areas, Close cooperation between the education system and the private sector to meet specific needs in firms, vocational training, involvement of local authorities, adequate remuneration, control and quality of work, strengthening of infrastructure, involvement of private firms in vocational education in the creation of future jobs, close and real cooperation between the private and local authorities, etc., limiting social assistance to those who really deserve it, reducing the contributions to the state generated by wages, specializing people in search of a job in different occupations, Provision of some form of protection for local employers from foreign employers, provision by the State of facilities (transport settlement, rent payments, etc.) to employees in rural areas or other locations in the south-east region, creation of training centers, creating jobs through private investment in sustainable projects, amending legislation, vocational training of employees, supporting young entrepreneurs, attracting nonreimbursable funds, modernizing the health system, opening up vocational schools, supporting the private environment to enter into partnerships with vocational schools, tax advantages private companies for 2-3 years through the employment of young people, higher requirements for graduates from teachers and the obligation for graduates to keep their jobs for at least one year, or on leaving to comply with all pay obligations, higher education levels in universities, financial incentives for employers to hire people with disabilities, associations between employers, possibly by field, creation of specific associations, lack of involvement of education policy, modernization of industry at national level, creation of conditions for migrants to return to the country, and constant cooperation between educational institutions (secondary schools/vocational schools/universities) and economic operators for the implementation of work placements both during the school year and on holidays, internship programs run by economic operators, active involvement of local business community leaders in the practical training of pupils/students through the participation of seminars, training in educational institutions, promotion of local business in educational institutions.

Correlation analysis of the key factors TQM, which are: Commitment of top management, continuous improvement, process management, customer focus, training and education, quality culture, policy and strategy, empowerment of employees and communication with seven barriers preventing the successful implementation of the TQM - weak understanding and insufficient knowledge of the TQM, Resistance to change, lack of delegation of authority and responsibility, lack of team work, lack of TQM experts, bureaucratic management and poorly inefficient preparation and development.

Key TQM factor; training and development with its subordinate TQM barriers. The related subordinate barriers to the resilience of the correlation from high to low have been listed. Providing quality training to managers, supervisors and employees would help reduce the negative impact of the following TQM barriers as there is unclear awareness of the TQM in the company, weaknesses in multi-functional cooperation and inter-department coordination, lack of experts and specialists in the TQM, Providing the necessary resources to cover the needs and development of employees would help overcome or reduce the negative impact of the following TQM barriers - lack of experts and specialists in TQM, lack of use of modern training methods at the company. Assessing training results regularly would help to combat or reduce the negative impact of the lack of use of modern training methods at company level.

The three most important labor problems that employers face at local level are the legislative framework, lack of labor, quality of educational services that are not permanently linked to the needs of employers in the local market. This study provides evidence from QM in higher education and provides useful information to those wishing to implement QM on critical factors influencing its successful implementation, which may face obstacles to its implementation, the possible practices they can take and the benefits they can benefit from.

\section{References}

1. Tan, A. H. T., Muskat, B., \& Zehrer, A. (2016). A systematic review of quality of student experience in higher education. International Journal of Quality and Service Sciences. 
2. Papanthymou, A., \& Darra, M. (2017). Quality management in higher education: Review and perspectives. Higher Education Studies, 7(3), 132-147.

3. Tetteh, G. A. (2019). Evaluating university leadership performance using Lean Six Sigma framework. International Journal of Lean Six Sigma, 10(4), 1018-1040.

4. Ibrahim, A. A., \& Abdalla, M. S. (2017). Educational management, educational administration and educational leadership: defin itions and general concepts. SAS Journal of Medicine (SASJM), 3(6), 2454-5112.

5. Kowalik, K., \& Klimecka-Tatar, D. (2018). The process approach to service quality management. Production Engineering Archives, 18(18), 31-34.

6. Kélada, J. (1990). La gestion intégrale de la qualité: pour une qualité totale. Quafec.

7. Porter, M. E., \& Advantage, C. (1985). Creating and sustaining superior performance. Competitive advantage, 167, 167-206. 